\title{
RETRACTED ARTICLE: Identification of Plastic Hinge Length for Pre-tensioning Confined HSC Columns
}

\author{
Chau-Khun Ma*, Abdullah Zawawi Awang**, and Wahid Omar*** \\ Published Online June 7, 2017
}

The article has been retracted by the Editor-in-Chief, the Society and the Publisher as it was published accidentally without consent of the Editor-in-Chief. The online version of this article contains the full text of the retracted article as electronic supplementary material.

*Senior Lecturer, Dept. of Structure and Material, Faculty of Civil Engineering, UTM Johor Bahr, Malaysia (Corresponding Author, E-mail: machaukhun@utm.my)

**Senior Lecturer, Dept. of Structure and Material, Faculty of Civil Engineering, UTM Johor Bahru, Malaysia (E-mail: abdullahzawawi@utm.my)

***Professor, Office of Chancellery, UTM Johor Bahru, Malaysia (E-mail: drwahid@utm.my) 